Article

\title{
Evaluation of Streamflow under Climate Change in the Zambezi River Basin of Southern Africa
}

\author{
George Z. Ndhlovu *(D) and Yali E. Woyessa (D)
}

check for

updates

Citation: Ndhlovu, G.Z.; Woyessa,

Y.E. Evaluation of Streamflow under Climate Change in the Zambezi River Basin of Southern Africa. Water 2021, 13, 3114. https://doi.org/10.3390/ w13213114

Academic Editor: Glen R. Walker

Received: 6 October 2021

Accepted: 31 October 2021

Published: 4 November 2021

Publisher's Note: MDPI stays neutral with regard to jurisdictional claims in published maps and institutional affiliations.

Copyright: (c) 2021 by the authors. Licensee MDPI, Basel, Switzerland. This article is an open access article distributed under the terms and conditions of the Creative Commons Attribution (CC BY) license (https:// creativecommons.org/licenses/by/ $4.0 /)$.

\author{
Department of Civil Engineering, Central University of Technology, Bloemfontein 9300, South Africa; \\ ywoyessa@cut.ac.za \\ * Correspondence: gndhlovu@cut.ac.za; Tel.: +27-515-073-072
}

\begin{abstract}
The Zambezi River basin is the fourth largest basin in Africa and the largest in southern Africa, comprising $5 \%$ of the total area of the continent. The basin is extremely vulnerable to climate change effects due to its highly variable climate. The purpose of this study was to evaluate the impact of climate change on streamflow in one of the sub-basins, the Kabombo basin. The multiglobal climate model projections were used as input to the Soil Water Assessment Tool (SWAT) hydrological model for simulation of streamflow under RCP 4.5 and RCP 8.5 climate scenarios. The model predicted an annual streamflow increase of $85 \%$ and $6 \%$ for high uncertainty and strong consensus, respectively, under RCP 8.5. The model predicted a slightly reduced annual streamflow of less than $3 \%$ under RCP 4.5 . The majority of simulations indicated that intra-annual and interannual streamflow variability will increase in the future for RCP 8.5 while it will reduce for the RCP 4.5 scenario. The predicted high and moderate rise in streamflow for RCP 8.5 suggests the need for adaptation plans and mitigation strategies. In contrast, the streamflow predicted for RCP 4.5 indicates that there may be a need to review the current management strategies of the water resources in the basin.
\end{abstract}

Keywords: catchment hydrology; global climate model; high uncertainty; streamflow simulation; strong consensus

\section{Introduction}

Climate change effects have now exacerbated the variable climate of Southern Africa. The changing climate has continued to alter the hydrology of the region to an extent where all water dependent sectors such as energy, agriculture, mining, municipal water supply, and tourism are affected. The current status of climate change impacts on hydrology calls for evaluation to enhance effective planning. The Zambezi River basin (ZRB) comprises 13 sub-basins, one of which is the Kabompo basin. The evaluation of the potential impact of climate change on future streamflow regime for Kabompo River basin is a prerequisite for water resources planning [1]. The basin has inadequate and inaccurate information on temporal and spatial variability of streamflow, especially regarding water availability, quality and maintenance of environmental flows [2]. The most common and widely used tools for understanding the historical climate conditions and projecting possible future climate changes under different emission scenarios are global circulation models (GCMs) [3]. The GCMs are described as mathematical representations of physical, biological and chemical fundamentals of the climate system [4].

The GCMs are used for representative concentration pathways (RCP), defined as a set of scenarios that have been adopted by climate researchers to provide possible future scenarios for the evaluation of the atmospheric composition [5,6]. Scenarios are detailed descriptions of how the future is likely to unfold in different social, economic, technological, environmental, greenhouse gas emission and climate settings [5]. There are four RCP that have been developed as climate scenarios, and these are RCP 2.6 as the lowest range, RCP 4.5 and RCP 6.0 as the middle range, and RCP 8.5 as the highest range [6,7]. Generating 
future climate scenarios using GCMs for local and regions of interests does not produce realistic results due to coarse spatial resolution, and will require downscaling to regional or local scales [5]. Downscaling is achieved through dynamic and statistical methods based on spatial and temporal climate projections. Several studies have shown that both dynamic and statistical downscaling techniques have similar characteristics [3]. Statistical downscaling is based on observed relationships between the current climate and future climate for a specific GCM. The result can be used to validate the results of the regional climate models (RCM) [3].

Prediction of future hydrology and water resources is based on downscaled GCM projections, which are used as input data in hydrological models to simulate hydrological variables, such as observed streamflow through calibration $[2,8]$. The complexity of river catchments with dynamic systems requires the development of a better understanding of how these systems will be altered with a changing climate [9]. Streamflow prediction can be achieved through the use of hydrological ensemble systems [10,11]. Assessments of impact of climate change on hydrology and water resources come with many uncertainties which can be attributed to emission scenarios, climate models, hydrological models, and downscaling methods [11,12]. Many times, uncertainties associated with climate models are larger than those of hydrological models or downscaling methods [13,14]. Uncertainty with hydrological prediction using GCM projections is better addressed with an ensemble system than a deterministic approach [15].

Several climate change impact studies have used the GCM ensembles to assess future streamflow. For instance, five GCMs were used in ZRB to analyse streamflow and found that part of the basin will experience decreasing percentage changes while some parts will have increasing percentage changes [16]. A large GCM ensemble data applied in the Zambezi River basin found that a series of potential impacts are more severe under RCP 8.5 than under RCP 2.6 or 4.5, indicating that Greenhouse Gas (GHG) mitigation may minimize uncertainties about the future climate scenarios, thereby reducing the risks of extreme changes as compared to the unconstrained emissions under RCP 8.5 [17]. GCM ensemble data were applied in Lake Victoria basin, Kenya and found that the range of change in mean annual rainfall of $2.4-23.2 \%$ corresponded to a change in streamflow of about 6-115\% [18]. GCM projections were applied in the Upper Zambezi River basin for analysis of catchment water balance components and it was concluded that there would be considerable precipitation increase leading to high runoff under RCP 8.5 and insignificant change under RCP 4.5 in some parts of the basin [19]. Three GCMs were used to analyse flood frequency in Kafue River basin within the ZRB based on simulated daily streamflow and it was concluded that in general, flood events increased during the B1 scenario (RCP 4.5) for 2021-2050 [20]. However, none of the studies had so far analysed in detail the streamflow variability on a high resolution for the Kabompo River basin under various time scales and climate change scenarios.

The objective of this study was to evaluate the impact of climate change on streamflow based on multi GCM projections with a view to minimize uncertainty. Six statistically downscaled and bias-corrected GCM projections under historical, RCP 4.5 and 8.5 climate scenarios were used as input to a calibrated Soil Water Assessment Tool (SWAT) hydrological model for the simulation of six-member ensemble streamflow. The simulated streamflow ensembles are based on the historical period 1975-2005, which was considered as the baseline, while RCP 4.5 and RCP 8.5 focused on 2020-2050. Land use and land cover were kept constant during SWAT simulations for RCP 4.5 and RCP 8.5, with climate change being the only factor influencing streamflow variability. The basin has insignificant changes in land/use land cover in the recent past due to limited development in the area. The largest land use/land cover has been wooded savannahs covering about $95 \%$ of the basin area. It is part of the rural area of the ZRB with huge potential for socio-economic development.

The results revealed two possible future scenarios for the Kabompo River basin based on high uncertainty and strong consensus. The high uncertainty scenario predicts high streamflow in the basin while strong consensus predicts slightly less streamflow than 
even the baseflow. Temperatures are also predicted to increase under both scenarios, which may lead to higher potential evapotranspiration. The study is considered a novelty in the detailed analysis of streamflow under high resolution for high uncertainty and strong consensus. The generated new knowledge for streamflow variability under various scenarios could be useful for future water resources planning for the basin and contribute towards water resources management strategies and a review of policies.

\section{Material and Methods}

\subsection{Study Area}

The Zambezi River basin (ZRB) has an area of 1,320,000 $\mathrm{km}^{2}$, making it the fourth largest river basin in Africa and the largest transboundary river in southern Africa that is shared by eight countries. This study focused on the Kabompo River basin (KRB), one of the sub basins, located in the Northwestern country of Zambia (Figure 1). The KRB forms part of the upper ZRB with an area of $72,087 \mathrm{~km}^{2}$ that is predominantly wooded savannahs as land use/land cover. Figure 1 shows the study area in Africa and the ZRB.

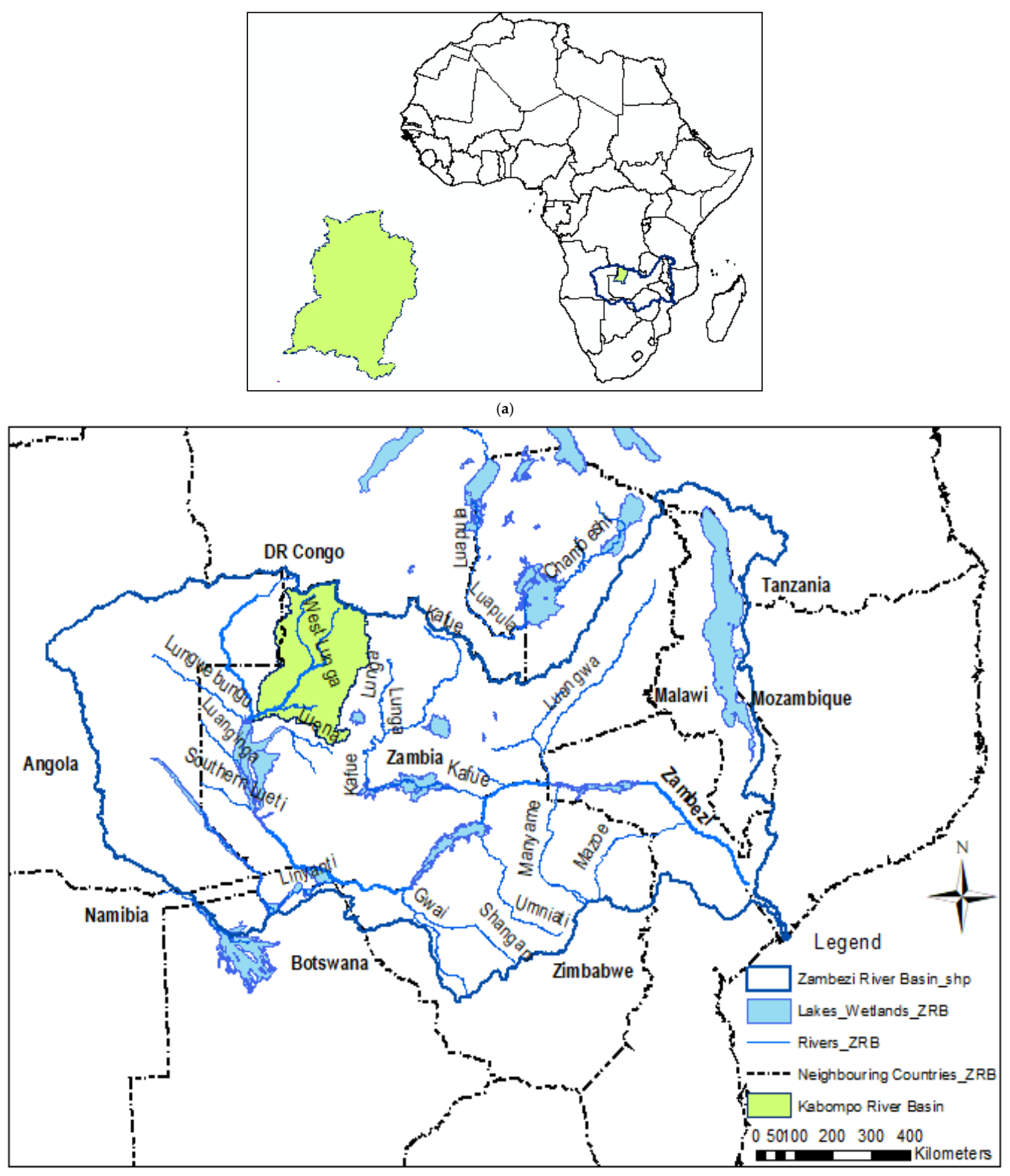

(b)

Figure 1. (a) Location of Study area in Africa. (b) The study area in the Zambezi River Basin [21]. 
The KRB has a humid and subtropical climate. This basin records average yearly rainfall of $1200 \mathrm{~mm}$, yearly average runoff of $100 \mathrm{~mm}$, and high river flows of $240 \mathrm{~m}^{3} / \mathrm{s}$ [22], making a significant contribution to surface water and groundwater resources in the entire Upper ZRB. According to previous studies [22,23], the runoff coefficient is very low in the ZRB and is usually less than $10 \%$ of the Mean Annual Precipitation (MAP) on average. The coldest month is July with mean monthly temperatures of less than $13{ }^{\circ} \mathrm{C}$, while October is the hottest month with a mean daily temperature of $29^{\circ} \mathrm{C}$. The potential evapotranspiration (PET) is estimated to be about $1300 \mathrm{~mm}$ [23]. The KRB has not been spared from global warming, as the decadal mean temperature rose in most of the $\mathrm{ZRB}$ ranges from $0.21^{\circ} \mathrm{C}$ to $0.33{ }^{\circ} \mathrm{C}$ between 1960 and 2006 [24]. The basin has a high potential for rain-fed and irrigated agriculture productivity and important potential sites for hydroelectric power generation such as Chikata falls in the Kabompo district, the Kabompo gorge (under construction), Nyamwezi Falls, and Muzhila Falls in the Mwinilunga district. The basin is also a home of an ecosystem with the West Lunga National Park, and economical centre of the country with large mines such as the Lumwana mine, (one of the largest mines in Africa), the Kalumbila mine and the Zabesha mine. The estimated population based on a 2010 census of the basin is 700,000 people with high poverty levels who rely on water resources for their livelihood. In view of the hydrological and social economic factors mentioned above, the KRB was identified to be strategic and hence chosen as a case study to demonstrate the impact of climate change on hydrology.

\subsection{Modelling Approach}

The modelling approach was adopted in the study where the SWAT calibrating hydrological model was forced with six GCM projections in simulation of streamflow. The six GCMs from Coupled Model Intercomparison Project Phase 5 (CMIP5) were statistically downscaled and used for climate change modelling. Figure 2 shows the flow diagram of the modelling approach.

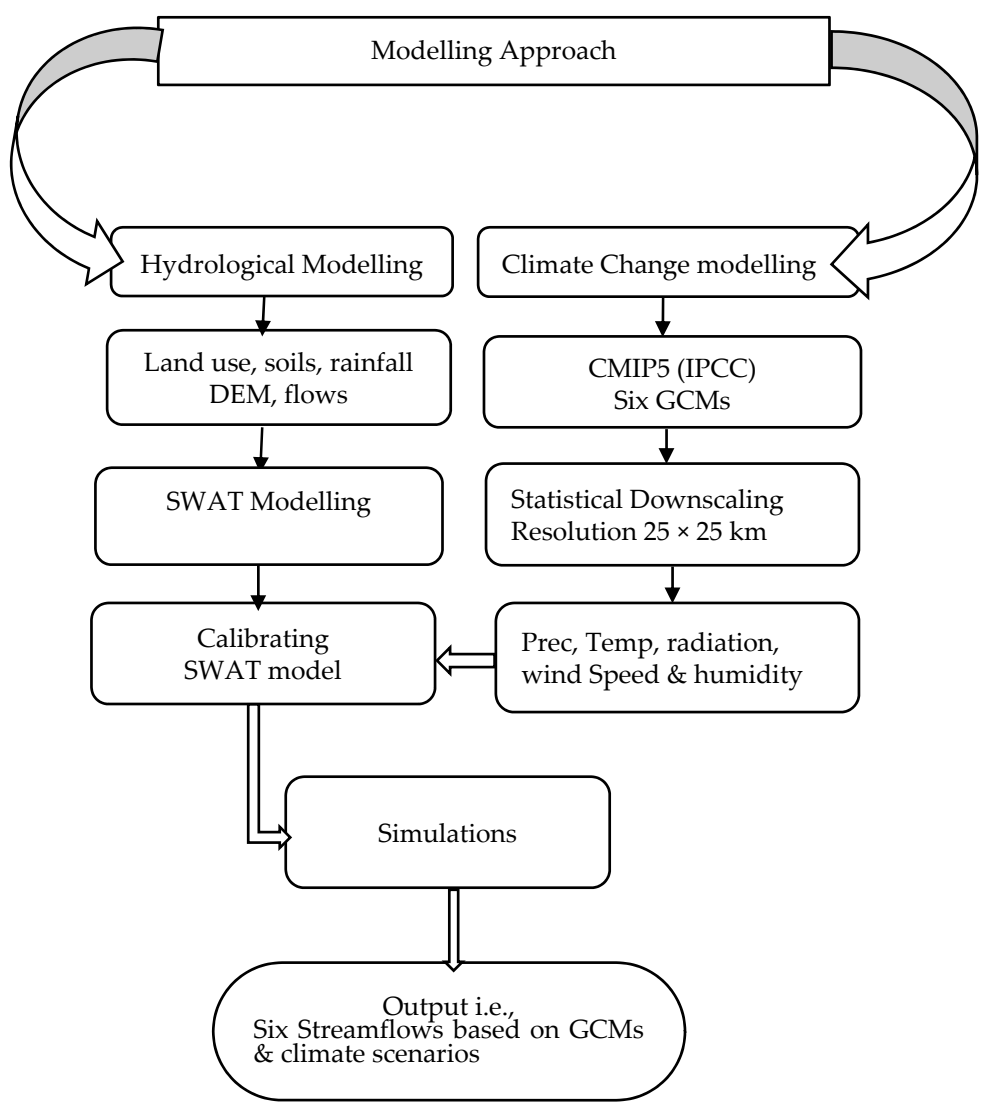

Figure 2. Modelling Approach. 


\subsection{Model Selection}

The Soil and Water Assessment Tool (SWAT) is a conceptual, continuous and distributed hydrologic model, which divides the basin into hydrological response units (HRU) based on the slope, soil characteristics and land use [25]. This model was selected for hydrological modelling because of its capability to do long-term simulations and wide application in climate change impact studies [26]. It is extensively used at a local, regional and global scale to simulate surface runoff, interception storage, groundwater flows, tile drainage, percolation and water quality [27]. The model is activity based and established to evaluate the impacts of management choices on water resources and nonpoint source pollution in river basins [28]. The SWAT model has shown to be applicable for hydrological modelling under various climatic and environmental conditions [29].

\subsection{Climate Data}

Daily climatic data such as precipitation, maximum and minimum air temperature, relative humidity, solar radiation, and wind speed are required to use the SWAT model for simulation of water balance components [30]. When measured climate data are not available or missing, SWAT simulates daily weather data to fill the missing data [31]. The analysis was based on future climate scenarios from six statistically downscaled and biascorrected GCMs, namely, Access1-0, CNRM-CM, IPSL-CM5A-LR, MIROC, MPI-ESM-MR and MRI-CGCM3-MR, under the RCP 4.5 and RCP 8.5 emission scenarios for the period of 2020 to 2050 [11]. These GCMs were obtained from the NASA Earth Exchange (NEX) Global Daily Downscaled Projections (NEX-GDDP). The NEX-GDDP dataset has a high spatial resolution of $0.25^{\circ}$ (approximately on $25 \mathrm{~km} \times 25 \mathrm{~km}$ ) and has been downscaled using global climate scenarios generated by GCM runs conducted through the Coupled Model Intercomparison Project Phase 5 (CMIP5) [32].

\subsection{Criteria for Selecting GCM}

In this paper, six GCMs, were considered for the development of multi-model ensembles for precipitation and temperature. The available literature has shown that there is no standardised procedure for the selection of the appropriate number of GCM for the multi-model ensemble and most of the studies considered the first three to ten GCM ranked according to descending order of their performance for the multi-model ensemble [33]. Several studies recommend that one GCM is not sufficient to evaluate uncertainties affecting the future projected climate. In view of this, an ensemble of GCM is a requirement in climate change impact studies [33]. The CMIP5 GCM runs were generated to support the Fifth Assessment Report of the Intergovernmental Panel on Climate Change (IPCC AR5). The selection of the GCM was based on a set of global, high resolution, bias-corrected climate change projections that could be used to assess climate change impacts on processes that are sensitive to finer-scale climate gradients and the influence of local topography on climate conditions [34].

\subsection{SWAT Model Set-Up}

The input data for the SWAT model included landuse/land cover obtained from USGS, the earth explorer, soil data obtained from FAO Africa, rainfall and temperature data obtained from Zambia Meteorological Department, Lusaka Zambia and DEM (with $30 \mathrm{~m}$ resolution) obtained from SRTM, and the USGS earth explorer. The set-up of the SWAT model was further subjected to performance evaluation using four performance indices that are normally used to assess the model performance. The indices include: Nash Sutcliff (NS), coefficient of determination $\mathrm{R}^{2}$, the $95 \%$ of predictive uncertainty (95PPU) known as the P-factor and the band representing observed data including its error. The $\mathrm{R}^{2}$ and NS is a probability degree for the SWAT model (rainfall runoff model) in the SUFI-2 technique between the simulated and observed stream flow. The P-factor was applied to measure the uncertainties associated with the SWAT model. The P-factor and R-factor are interrelated such that a larger P-factor can only be obtained at the expense of a higher 
R-factor [35]. Properties of error in average basin precipitation and simulated runoff is described using three evaluation metrics, namely Mean Relative Error (MRE), Centered Relative Root-Mean-Square Error (CRMSE), and Correlation Coefficient (CC). MRE is an error metric measuring the systematic error component with values greater or smaller than zero indicating over- or underestimation, respectively [36]. Monthly model performances are further evaluated using the ratio of the root mean square error to the standard deviation of observed data, and the percent bias (PBIAS). Bias ratio is the average of the ratio of the predicted value to the actual value. The bias ratio of a real unbiased distribution will be one (1) [37].

The calibrating SWAT model was driven by all six downscaled and bias-corrected climate projections to simulate future streamflow for the basin [38]. The model inputs of daily climatic data for the baseline and future climate scenarios included precipitation, maximum and minimum temperature, solar radiation, relative humidity and wind speed. The first three-year period was used as a model warm-up period and, therefore, simulations were run from 2023 to 2050, while the baseline period covered 1978 to 2005. The calibrated SWAT model used inputs from six GCM projections under the baseline, RCP 4.5 and RCP 8.5 climate scenarios and simulated monthly streamflow $\left(\mathrm{m}^{3} / \mathrm{s}\right)$. Streamflow in the SWAT model was obtained by summation of surface runoff, interflow and base flow [2]. The simulated streamflow was then used as an ensemble for quantification and analysis based on monthly, seasonal and annual time scales. In addition, the study focused on lower time resolution rather than on daily simulations, because the GCM's reliability decreases at higher frequency temporal scales [39].

\subsection{Assessment of Climate Change Impact}

Many methods have been developed to assess the impact of climate change on global or regional scale. The most commonly used method is the change factor methodology (CFM), which is also called delta change factor method [39]. Although CFM is commonly used to assess the future climate scenarios, there are no properly described procedures that exist in the literature that can be employed to identify the most appropriate methodology for different applications [39].

The mathematical formulation procedure was used as CFM, which can be additive or multiplicative. The additive CFM is determined by finding the change of a GCM variable resulting from a recent climate simulation and a future climate scenario based on the identical GCM grid position. The calculated change (delta change) is then added to the measured data to find the simulated future time series.

The additive change factors involve estimation of averages for baseline and future scenarios using Equations (1) and (2), respectively [16,39].

$$
\begin{aligned}
& \overline{G C M_{b}}=\sum_{i=1}^{N_{b}} \frac{G C M_{b i}}{N_{b}} \\
& \overline{G C M_{f}}=\sum_{i=1}^{N_{f}} \frac{G C M_{f i}}{N_{f}}
\end{aligned}
$$

where

$G C M_{f i}$ and $G C M_{b i}$ are values from future and baseline scenarios, respectively, for a temporal domain; and $\overline{G C M_{f}}$ and $\overline{G C M_{b}}$ are mean values of the future and baseline climate, respectively.

In order to calculate the additive change factor, Equation (3) is used.

$$
C F_{a d d}=\overline{G C M_{f}}-\overline{G C M_{b}}
$$

The above equations were applied in this paper to determine the changes that are due to climate change. 


\subsection{Coefficient of Variation}

Intra-annual and inter-annual variability of streamflow at the KRB outlet was analysed with the coefficient of variation (CV) for each GCM to determine the distribution of the streamflow around the mean.

\section{Results and Discussion}

\subsection{SWAT Model Calibration, Validation and Uncertainty Analysis}

The SWAT model was calibrated and validated with observed streamflow for the periods of 1982-1997 and 1998-2005, respectively. The goodness of fit was assessed with the Nash-Sutcliff (NS) method [40] The statistics obtained after calibration showed Nash Sutcliff (NS) of 0.73 , and coefficient of determination $\left(\mathrm{R}^{2}\right)$ of 0.73 . Further statistics obtained after validation showed NS of 0.64 , and $\mathrm{R}^{2}$ of 0.70 , The results indicate that all efficiency parameters are good since they exceed $0.6[24,28,41]$. KRB was delineated with 255 HRUs, 102 sub-basins and a total area of $72,087 \mathrm{~km}^{2}$ using SWAT model. During the calibration and validation processes, the model was further analyzed for uncertainty using the sequential uncertainty fitting algorithm (SUFI-2) [42]. The 95\% of predictive uncertainty (95PPU) was well-bracketed during the calibration period of 1982 to 1997, with a P-factor of 0.75 and an R-factor of 0.75 , while during the validation period of 1998 to 2005 , the values changed to 0.73 and 0.55 , respectively. The P-factor of 0.75 obtained during calibration and 0.73 during validation indicate that most of the observed and simulated data are bracketed with 95PPU. The slight decrease in P-factor from 0.75 to 0.73 during validation indicates the level of uncertainties in input variables, such as rainfall. Further statistics, including RSR, and PBIAS, were used to evaluate the monthly model performances. During calibration, RSR was found to be 0.52 and PBIAS -2.2 while validation RSR slightly increased to 0.60 and PBIAS increased to 9.4.

The model was analyzed successfully used aforementioned statistics with a goodness of fit to real data measured, and therefore the objective function was reached. After the SWAT model calibration and validation were completed, six bias-corrected and statistically downscaled baseline and future climate projections, derived from the GCMs, were used as inputs to the SWAT model [34].

\subsection{SWAT Simulation}

\section{High Uncertainty and Strong Consensus}

The SWAT simulated results, based on the six GCM projections, showed considerable variations in monthly streamflow under RCP 8.5, RCP 4.5, and baseline climate scenarios. The SWAT streamflow simulation for ensemble GCM under RCP 8.5 showed much higher flows when using Access1-0 than the remaining five GCMs, giving a consensus of $83 \%$ based on five GCMs out of six (5/6). Therefore, results under RCP 8.5 have been separated as two cases of five GCM with strong consensus and six GCMs (including Access1-0) with high uncertainty, while the remaining results for baseline and RCP 4.5 are presented as the same six-member ensemble.

The RCP4.5 is a middle pathway scenario that corresponds to guidelines of lower greenhouse gas emission by the international community. The RCP 8.5 is a high emission scenario, which indicates high impact on climate change. RCP 4.5 and RCP 8.5 together provide a good overview of possible impacts. The streamflow increased by about $80 \%$ under RCP 8.5 with high uncertainty, while for the strong consensus case, it increased by $12 \%$, because this is the unrestricted emission scenario. Predictions of streamflow are generally high under Access1-0 for RCP 8.5 and only moderately increased for the remaining GCM (strong consensus) such that the calculated average flows are generally higher than the baseline ensemble mean streamflow. The predicted streamflow indicates an extreme weather event in the basin, which experiences the highest rainfall in the region culminating in periodic floods.

The streamflow results for RCP 8.5 showed uncertainty in magnitude, which was observed by other researchers who stated that there is uncertainty in magnitude and 
direction of change in the Zambezi River basin response to future GCM projections [43,44]. It was pointed out that GCM runs performed under RCP 8.5 result in more uncertainty than under RCP 4.5 because of climate distribution [17]. Although Access1-0, under RCP 8.5, showed a higher uncertainty, the simulation results for baseline and RCP 4.5 scenarios were within the same range with all other GCM. Differences exist only for RCP 8.5 due to the sensitivity of the unrestricted GHG emissions policy. However, the selected model satisfied the GCM selection criteria and may therefore not be considered as simply producing streamflow results that could be regarded as outliers.

Many earlier studies recommend that previous performance evaluation is one of the most appropriate methodologies since the GCMs that are finest in simulating the baseline climatic scenarios are most likely to predict the future climate $[33,45]$. Therefore, the high streamflow simulated for RCP 8.5 is a direct response to high precipitation input for KRB, and Access1-0 was therefore considered to have a unique ability in simulations [1]. The results for Access1-0 under RCP 8.5 were therefore presented as a case for high uncertainty.

Meanwhile, the ensemble GCM simulations under the RCP 4.5 scenario were within the similar range with minor differences. The baseline GCM simulations and their ensemble were found with similar patterns and within the same range with ensemble GCM simulations under RCP 4.5. However, the magnitude and regime of the ensemble SWAT simulated streamflow under the RCP 4.5 scenario does not significantly differ from the ensemble baseline streamflow, suggesting that there may be insignificant variations in hydrological variables, such as water yield, surface runoff, groundwater flow and interflow. This result for RCP 4.5 is similar to previous studies that suggest that streamflow in the ZRB is likely to remain within the ranges of historically observed variability [45]. The results for the RCP 4.5 scenario may also be comparable to a previous study on median change in rainfall that projected to be close to no change in the ZRB for both RCP 4.5 and RCP 8.5 climate scenarios [17]. Further previous studies in the ZRB generally predicted rising temperatures and precipitation decrease and that season may become shorter and more variable, predicting more extended drought periods and more severe floods [43]. The results under RCP 4.5 also agree with previous climate change impact studies that used five GCM (CGCM3.1, CSIRO3.0, ECHAM5, CCSM3.0 and HACDM3), and concluded that the $\mathrm{ZRB}$ will have increased temperatures and decreased precipitation leading to reduced streamflow according to a special report on emission scenario A1B (SRES A1B) [18].

The findings in this paper show an average temperature rise of $1.6^{\circ} \mathrm{C}$ under RCP 8.5 and $1.3^{\circ} \mathrm{C}$ under RCP 4.5 for the same time period. The average temperature for the baseline scenario was used as reference for the estimation of the temperature change. The temperature rise of $1.6^{\circ} \mathrm{C}$ is significant as it comes with huge effects on evapotranspiration and is likely to lead to general dryness in some areas of the basin. The result confirms the findings of the previous studies which predicted that the mean monthly potential evapotranspiration would increase in the future $[3,44]$. Despite the increase in temperature, the patterns across the basin remain similar to the baseline climate for the winter season in June, July and August (JJA) and summer season in September, October and November (SON).

\subsection{Annual Streamflow Analysis}

The different GCM projections were used as input for simulation of future streamflow by SWAT model for the baseline, RCP 4.5 and RCP 8.5 climate scenarios to show variations and patterns. The results under RCP 8.5 were separated for strong consensus and high uncertainty to demonstrate future possibilities for the ZRB. The simulated results include the calculated averages as shown in Figure $3 a-d$ to highlight variations about the mean and patterns. 

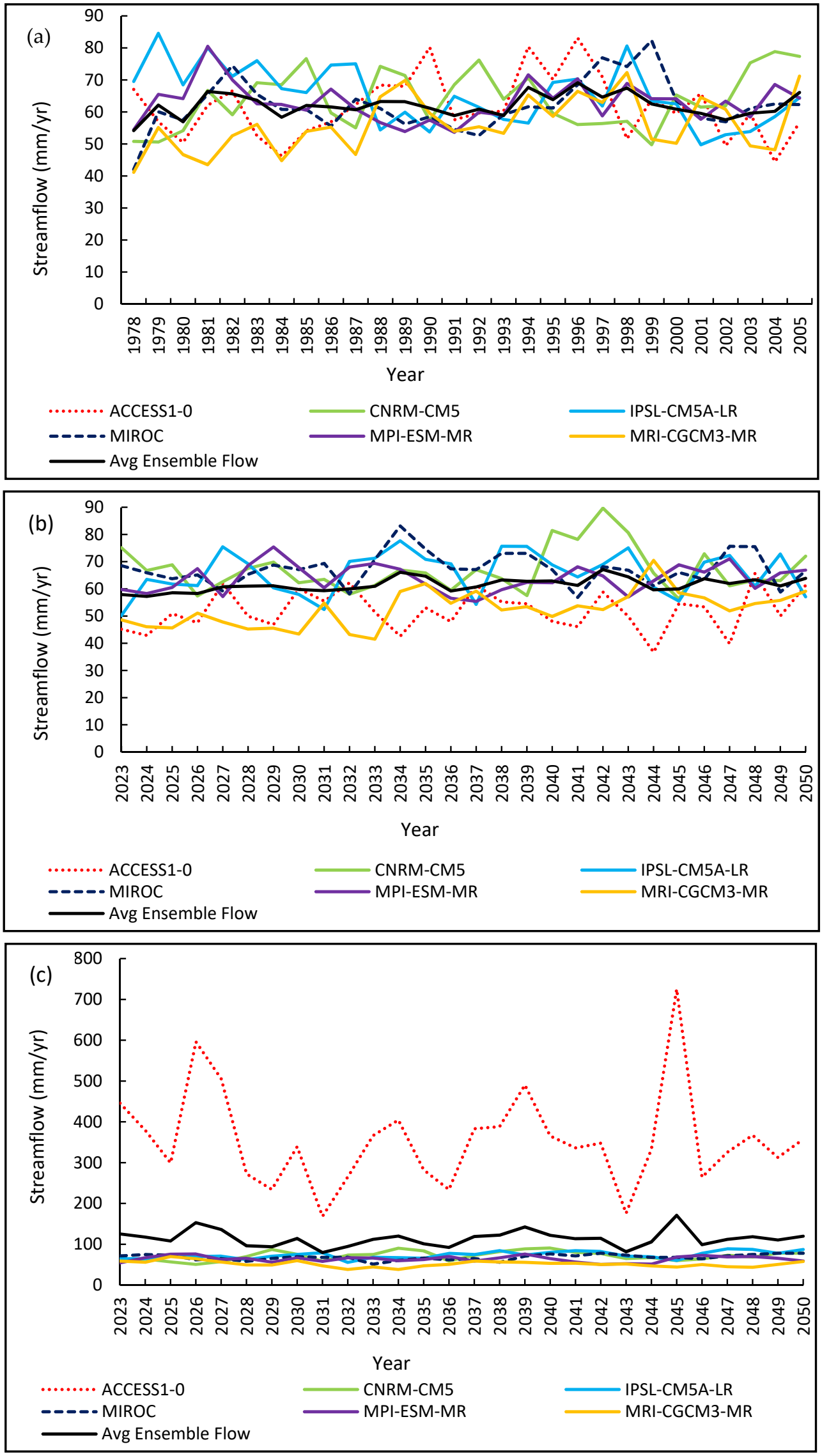

Figure 3. Cont. 


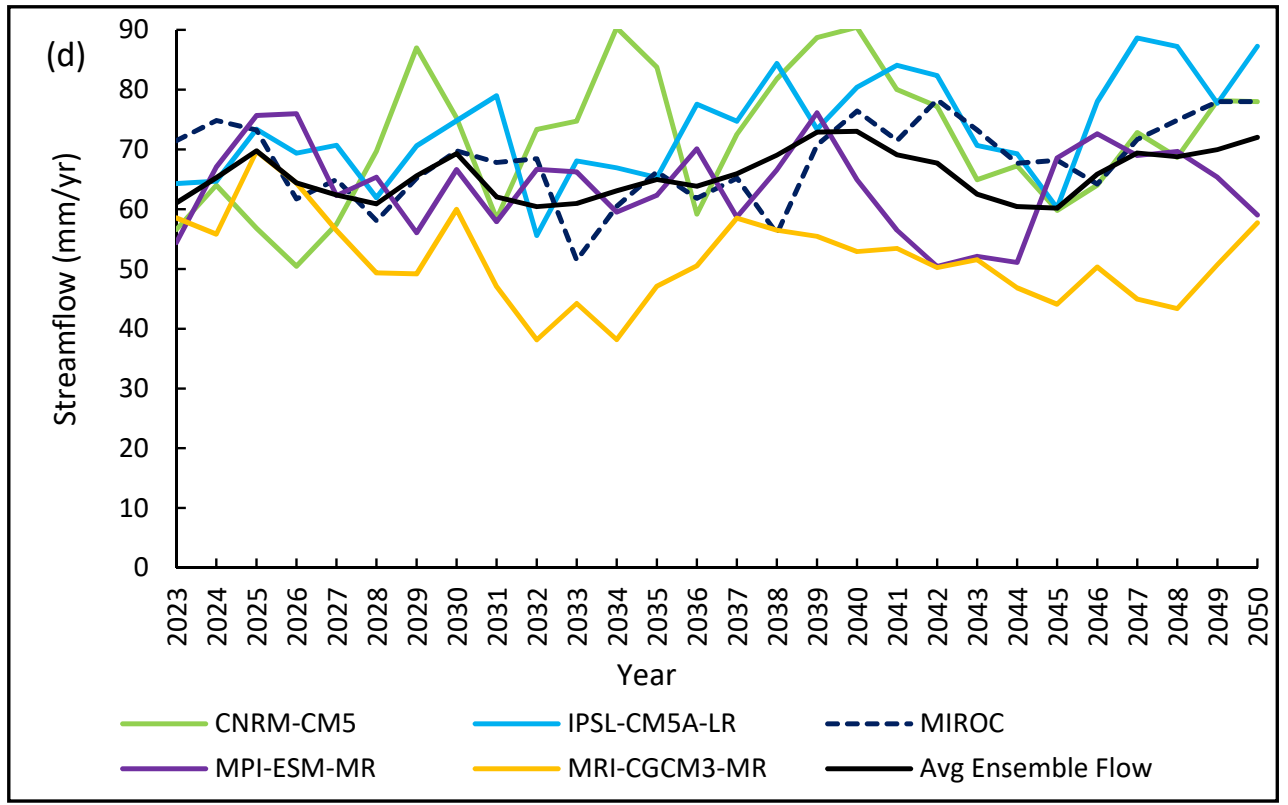

Figure 3. (a) Baseline ensemble streamflow with the average; (b) RCP 4.5 ensemble streamflow with the average; (c) RCP 8.5 ensemble streamflow based on high uncertainty with the average; and (d) RCP 8.5 ensemble streamflow based on strong consensus with the average.

The streamflows based on the GCM baseline, the RCP 4.5 and RCP 8.5 strong consensus scenario in Figure 3a,b,d show similar patterns in the annual streamflow simulations that are in the same range of magnitude between 30 and $90 \mathrm{~mm} /$ year across the basin. Figure $3 \mathrm{c}$ indicates that the GCM ensemble was significantly different as the streamflow simulation based on Access1-0 is higher and in the range of 168-725 mm/year across the basin with a different pattern. The differences in simulations for RCP 8.5 may demonstrate uncertainty in non-perfectly calibrated model and GCMs that have various model characteristics [1].

\subsection{Monthly Streamflow Analysis}

Figure 4a indicates the monthly streamflow, based on Access1-0 for the RCP 8.5 scenario that has a high uncertainty, with the highest magnitude of $1696 \mathrm{~m}^{3} / \mathrm{s}$ compared to the baseline and RCP 4.5. The highest simulated streamflow occurs in January while, in February and March, the flow begins to recede until August, when it becomes similar to the base flow. The lowest flow of $204 \mathrm{~m}^{3} / \mathrm{s}$ is experienced in September and October. Thereafter, the flow begins to rise gently up to November, where there is a sharp rise due to rainfall events starting towards the end of September.

The peak baseline streamflow is $224 \mathrm{~m}^{3}$ /s occurring in March while peak streamflow for the RCP 4.5 scenario in the same month is $187 \mathrm{~m}^{3} / \mathrm{s}$. The baseline streamflow is slightly higher than that of the RCP 4.5 throughout the year, predicting a decrease in flow magnitude under RCP 4.5. The lowest flow for both baseline and RCP 4.5 is $73 \mathrm{~m}^{3} / \mathrm{s}$ in November. Figure 4a under RCP 8.5 (high uncertainty) shows a shift in the peak flow occurrence when compared to the other three scenarios. The peak flow for RCP 8.5 in Figure $4 \mathrm{a}$ is predicted to be in January, while the baseline, RCP 4.5 and RCP 8.5 (Figure 4a') scenarios have a corresponding peak flow in March. There is also a sharp rise in flow predicted for the RCP 8.5 scenario for the period between November and January, which may be triggered by a high rainfall input at the beginning of October. Figure $4 a^{\prime}$ indicates the monthly streamflow based on Access1-0 under RCP 4.5 and a baseline that has strong consensus and shows similar pattern as all other GCM streamflows. 

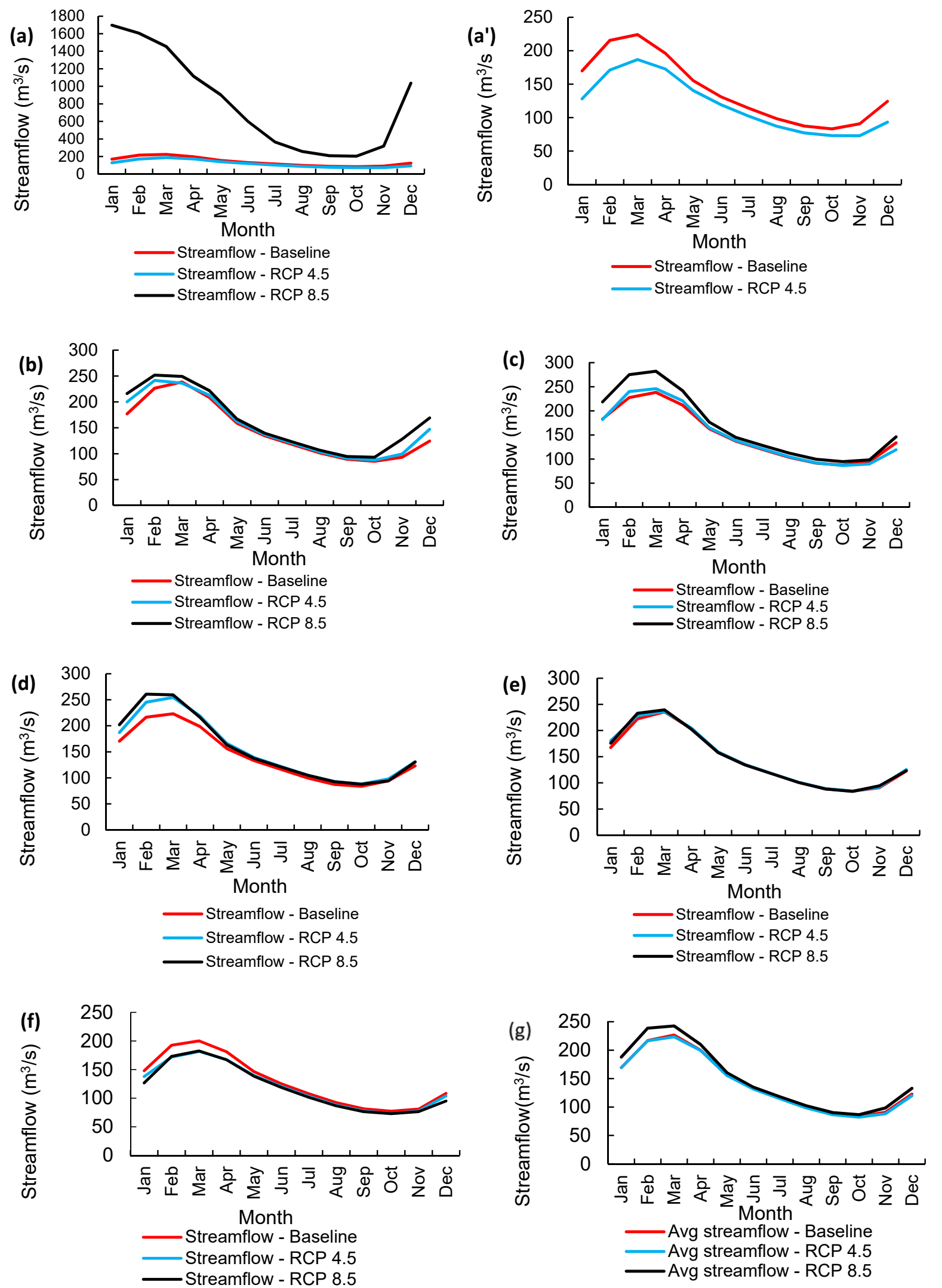

Figure 4. Streamflow simulations based on individual global climate models: (a) ACCESS1-0 (high uncertainty); (a') ACCESS1-0 (strong consensus); (b) CNRM-CM; (c) IPSL-CM5A-LR; (d) MIROC; (e) MPI-ESM-MR; (f) MRI-CGCM3-MR; and $(\mathrm{g})$ average streamflow for GCM Ensemble. 
Figure 4c shows the prediction of streamflow based on IPSL-CM5A-LR for the RCP 4.5 and RCP 8.5 scenarios. The streamflow simulations have nearly the same flow regime, with some differences between January and April. The streamflow for RCP 8.5 is higher than the ones for both RCP 4.5 and the baseline, which are almost comparable to one another throughout the year. Figure $4 \mathrm{~d}$ shows the prediction of streamflow based on MIROC5 under the RCP 4.5 and RCP 8.5 scenarios compared to the baseline period. The three streamflow simulations have nearly the same magnitude and flow regime with some differences between January and April. The streamflow for RCP 8.5 is slightly higher than for RCP 4.5, which is also higher than the baseline streamflow between January and April.

Figure $4 \mathrm{e}$ shows no variation in the streamflow simulated for the baseline period, the RCP 4.5 and RCP 8.5 scenarios and therefore predicts no changes in streamflow for the near future. Figure $4 \mathrm{f}$ shows the streamflow for RCP 4.5 and RCP 8.5 will be considerably less between January to April, while slightly less for the rest of the months when compared to the baseline.

Figure $4 \mathrm{~g}$ shows the average streamflow for ensemble GCM based on baseline, RCP 4.5 and RCP 8.5 with strong consensus. The streamflow simulation based on the GCM shows that the future magnitude of streamflow will reduce slightly between the months of May and December, while considerable reductions will occur between January and April.

Overall, Figure 4 shows most of the streamflow simulations, based on five GCM, predict slight increases in streamflow, while streamflow simulations based on Access1-0 (Figure 4a) predict a considerable increase, and streamflow simulations based on MRICGCM3-MR predict slightly less streamflow. The streamflow simulations in Figure 4a are within the same range while streamflow simulations in Figure 4a have an enormous increase when compared to other GCMs. Further analysis was therefore performed to calculate monthly streamflow ensemble means based on the six GCM in Figure 5 for the baseline as well as the RCP 4.5 and RCP 8.5 climate scenarios as it improves the outcome of simulations [46].
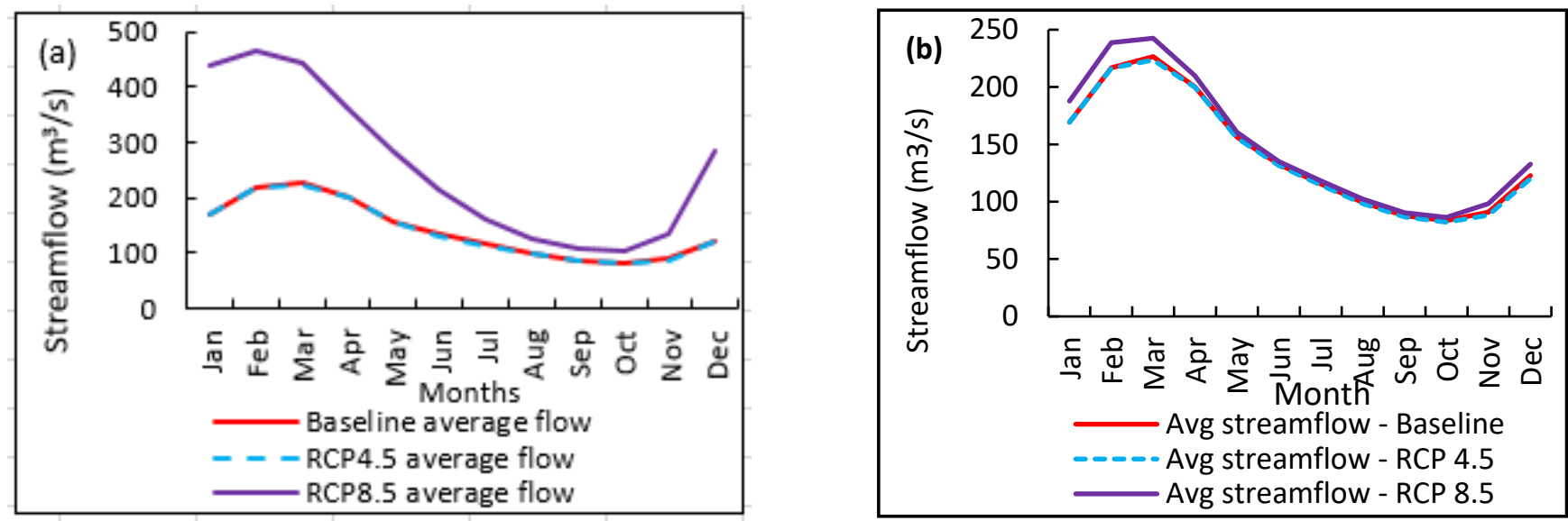

Figure 5. Monthly mean streamflow ensembles under (a) high uncertainty and (b) strong consensus.

The mean streamflow ensembles shown in Figure 5a,b indicate that the baseline and RCP 4.5 streamflows will have insignificant variations in magnitude and flow regime although the stream flows for RCP 4.5 will be slightly less than baseline streamflow. Meanwhile, the mean streamflow for RCP 8.5 with high uncertainty will be much higher in magnitude than the two ensemble mean streamflows with a wide variation in flow regime. The RCP 8.5 with strong consensus on Figure $5 \mathrm{~b}$ shows a moderate increase in monthly streamflow and with a similar pattern with Baseline and RCP 4.5 streamflow ensembles. The simulated flows are within the range of the other GCMs.

The ensemble mean streamflow for RCP 8.5 indicates a sharp rise from November to January, while for RCP 4.5, there is a moderate rise from November to January. The predictions from the ensemble mean streamflow indicate an increased magnitude of streamflow 
for RCP 8.5, which may culminate into flooding of most parts of the basin depending on topography, whereas RCP 4.5 generally indicate a slightly lower streamflow when compared to the baseline flow. In order to determine the actual increase or decrease of the ensemble mean streamflow in Figure 6, the change factor methodology (CFM) [39] was applied.
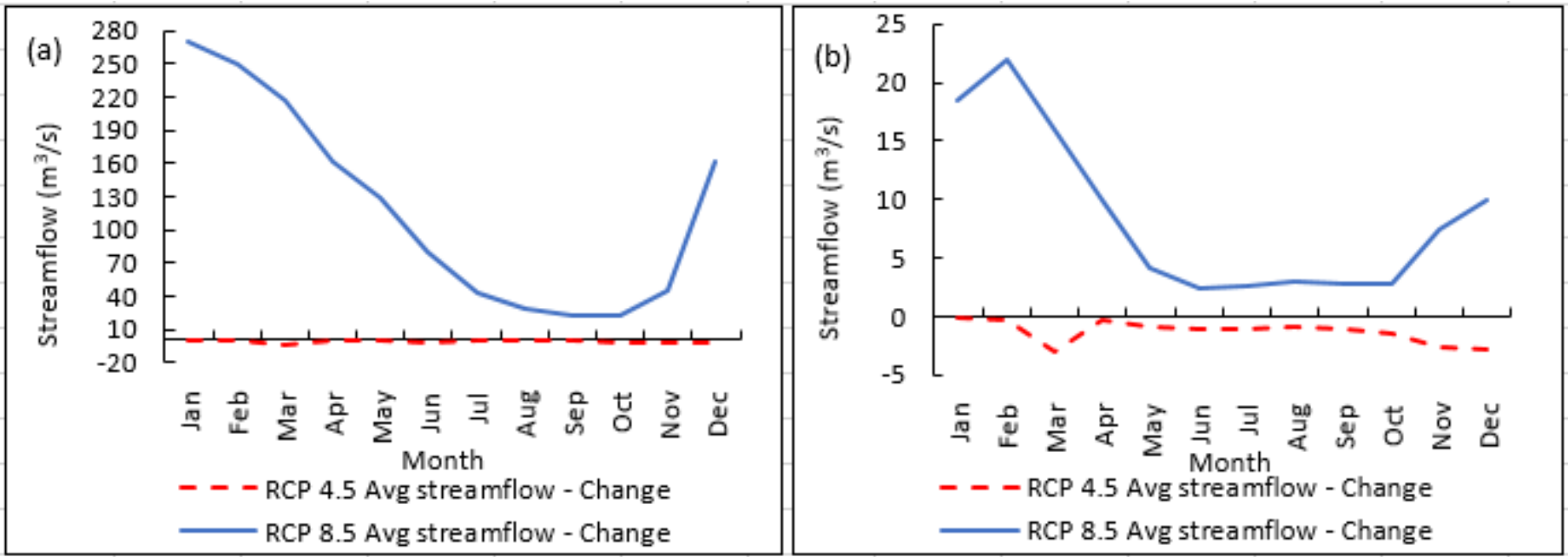

Figure 6. Ensemble mean streamflow changes (a) under high uncertainty; and (b) strong consensus.

Figure 6a shows the highest streamflow of $270 \mathrm{~m}^{3} / \mathrm{s}$ for RCP 8.5, which is much higher than the ensemble means of that of RCP 4.5. The highest increase in streamflow occurs in January, while the lowest increase occurs in September and October. Prediction of the flow regime shows that peak flow occurs in January and recedes gently until September before beginning to rise again in November. Figure $6 \mathrm{~b}$ shows the highest increase in streamflow of $25 \mathrm{~m}^{3}$ /s for RCP 8.5 to be moderately higher than the streamflow for RCP 4.5 .

\subsection{Seasonal Flow Analysis}

The KRB experiences four seasons, namely December, January and February (DJF) representing the typical rainy season (spring); March, April and May (MAM) indicating the autumn season; June, July and August (JJA) representing the winter season; and finally, September, October and November (SON) representing summer.

Streamflow varies depending on the season. DJF and MAM are known as wet seasons, while JJA and SON are known as dry seasons. Future streamflow from the GCM ensemble means were analyzed based on the aforementioned seasons and monthly future streamflows. The CFM was applied to monthly streamflow and aggregated to seasonal streamflow. Figure 7 shows the seasonal comparisons between baseline, RCP 4.5 and RCP 8.5 stream flows under high uncertainty and strong consensus with corresponding changes per season. 

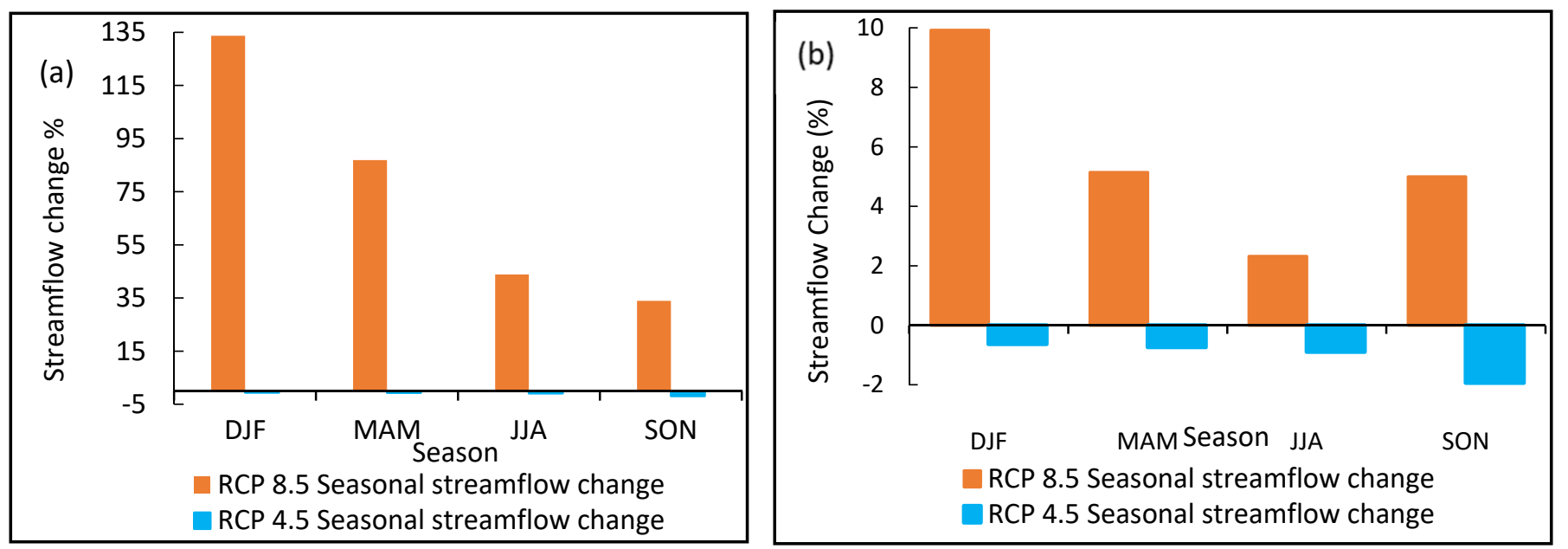

Figure 7. Comparisons of change in seasonal streamflow for (a) high uncertainty; and (b) strong consensus.

The seasonal streamflow in Figure 7 indicates that for RCP 4.5, streamflow will be reduced by $-0.6 \%$ in DJF, $-0.7 \%$ in MAM, $-1 \%$ in JJA and $-2 \%$ in SON in both scenarios. The seasonal streamflow will be slightly less than the historical flow because all seasons have been predicted with an increasing negative magnitude, with highest occurrence in $\mathrm{SON}$ at $2 \%$ reduction.

However, the seasonal streamflow for RCP 8.5 is apparently high for all seasons in contrast to the baseline and RCP 4.5 stream flows. The highest seasonal streamflow change in Figure $7 \mathrm{a}$ is predicted to be $134 \%$ for DJF, which is followed by $87 \%$ for MAM, $44 \%$ for JJA and $34 \%$ for SON. This implies that DJF and MAM may experience severe floods, whereas JJA and SON represent the dry season where the streamflow does not significantly differ from the baseline flow. Predictions in Figure $7 \mathrm{~b}$ show that seasonal streamflow will increase in DJF by $10 \%$, MAM by $5 \%$, JJA by $2 \%$ and SON by $5 \%$. All percentage calculations are based on baseline data.

The results show consistency with previous studies which predicted that, under the RCP 8.5 scenario for the period 2020-2050, most part of the ZRB is likely to experience dryness, apart from areas in the north (close to Malawi and Northern Zambia), which will be wetter and therefore leading to high streamflow $[15,17]$. As the KRB is located in the North-western part of Zambia, the results agree with the findings on the rise of extreme events in most ZRB riparian states that included Malawi, Zambia and Mozambique [47]. Others previous studies predicted a significant increase in rainfall events over Southern Africa (including Angola, Namibia, Mozambique, Malawi and Zambia), which will lead to more streamflow $[48,49]$.

\subsection{Intra-Annual Flow Analysis}

Concerning the monthly streamflow simulation for six GCM, the intra-annual variability showed a uniform pattern of streamflow indicating significant correlation efficiency. The streamflow simulation in Figure 8 shows monthly streamflow variability for six GCM based on RCP 8.5 and with significant differences between high uncertainty and strong consensus.

The simulated streamflow in Figure 8a shows that monthly streamflow for Access 1.0 is much higher than the majority, suggesting uncertainty and confirming that different GCM respond differently to model formulations for dynamics, physics (i.e., parameterizations) and external forcing. Figure $8 \mathrm{~b}$ shows that the simulations from the GCM are similar and give a uniform pattern throughout the period of projection. The simulated monthly flows were aggregated to ensemble mean annual flows in Figure 9 to analyze the annual variability for the three climate scenarios. 

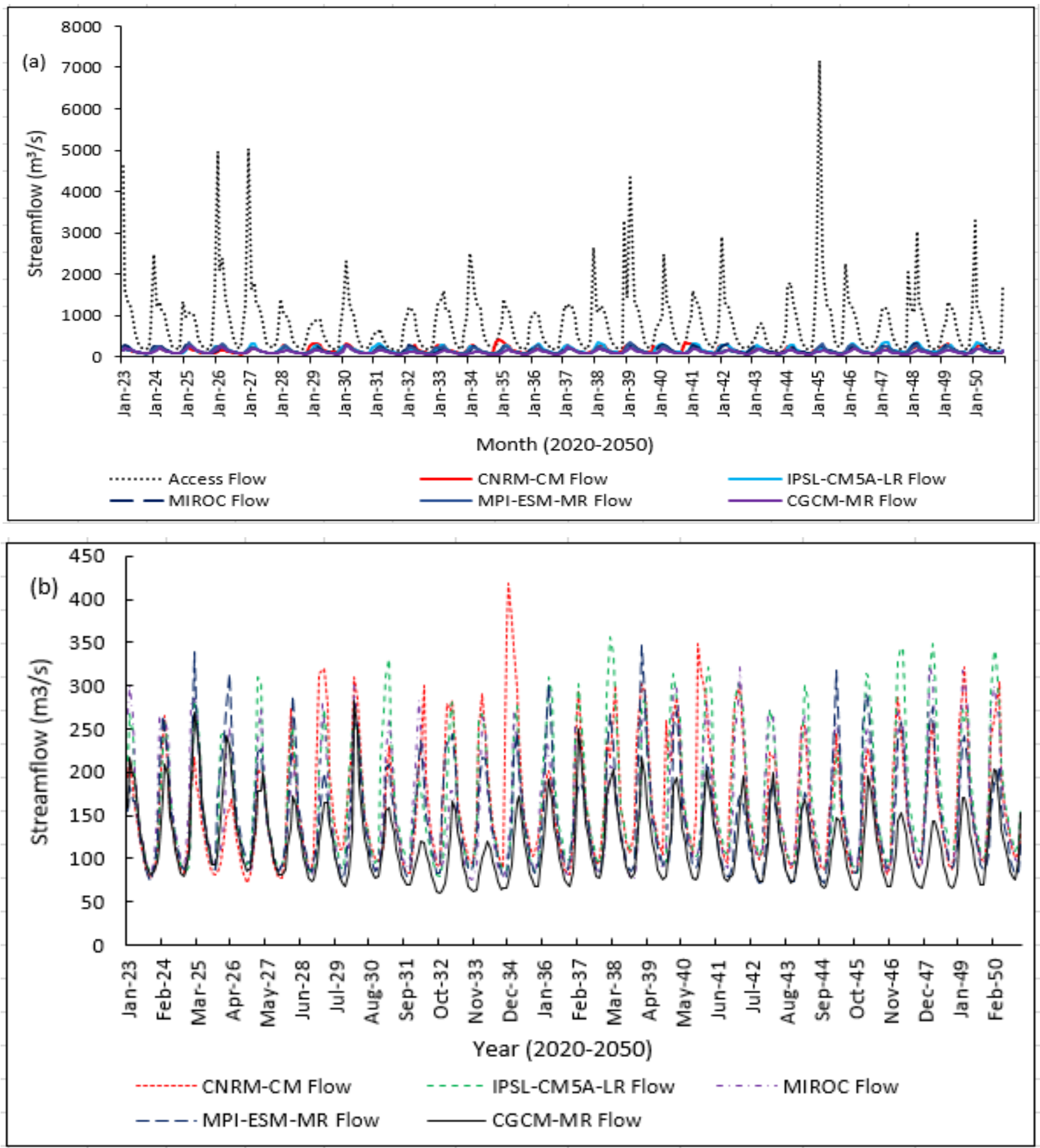

Figure 8. Monthly streamflow for RCP 8.5 for (a) high uncertainty; and (b) strong consensus.

The ensemble mean annual flows in Figure 9a are predicted to be high for RCP 8.5 with high uncertainty compared to the ensemble mean for both RCP 4.5 and baseline. Figure 9a shows that annual flows for RCP 4.5 and baseline have insignificant differences in magnitude and regime. The ensemble mean annual streamflow for RCP 4.5 in Figure 9a,b predicts a slight reduction when compared to the baseline streamflow. This result is consistent with the previous study which predicted that on average the annual rainfall in the ZRB (about $960 \mathrm{~mm}$ ) will decrease across the ZRB, which is expected to reduce runoff [16], while others predicted from the baseline runoff data that it will decrease by 2050s [44]. Researchers predicted that ZRB would result in a decline in water runoff with consequent reductions in streamflow under RCP 4.5 by 2100 [49]. 

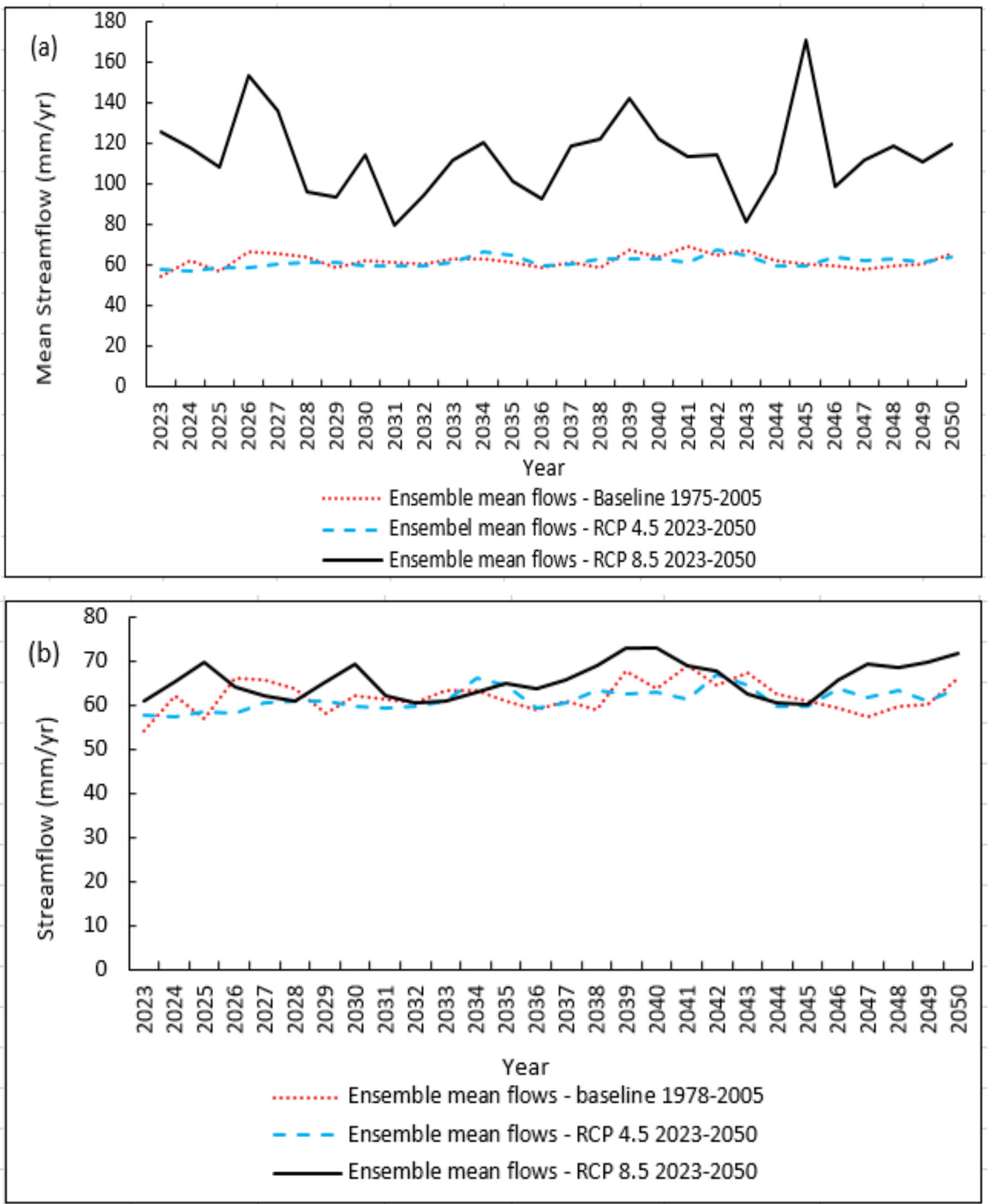

Figure 9. Ensemble mean annual flows for (a) high uncertainty; and (b) strong consensus.

\subsection{Intra-Annual and Inter-Annual Streamflow Variability}

Flow regime analysis has always been critical in the environmental sciences to enhance the understanding of streamflow variability [50]. Intra-annual variability of baseline, RCP 4.5 and RCP 8.5 stream flows were determined for each GCM to assess the distribution around the mean, which was calculated as Coefficient of Variation (CV). Table 1 indicates the estimated $\mathrm{CV}$ for various stream flows for different climate scenarios. All the CVs for the RCP 4.5 scenario are lower than that of the baseline scenario. Therefore, 
most simulations indicate that intra-annual and inter-annual streamflow variabilities will decrease for RCP 4.5 in the future.

Table 1. Estimated coefficient of variation (CV).

\begin{tabular}{|c|c|c|c|c|c|c|c|c|c|}
\hline GCM. & Access & $\begin{array}{c}\text { CNRM } \\
\text { CM5 }\end{array}$ & $\begin{array}{c}\text { IPSL } \\
\text { CM5A } \\
\text { LR }\end{array}$ & MIROC & MPI-ESM-MR & MRI-CGCM3-MR & $\begin{array}{c}\text { Highest } \\
\text { CV }\end{array}$ & $\begin{array}{c}\text { Mean } \\
\text { CV }\end{array}$ & $\begin{array}{c}\text { Lowest } \\
\text { CV }\end{array}$ \\
\hline & \multicolumn{9}{|c|}{ Baseline scenario } \\
\hline Intra-annual CV & 0.410 & 0.413 & 0.404 & 0.387 & 0.386 & 0.396 & 0.413 & 0.399 & 0.386 \\
\hline Inter-annual CV & \multicolumn{9}{|c|}{ RCP 4.5 Scenario } \\
\hline Intra-annual CV & 0.399 & 0.401 & 0.419 & 0.406 & 0.384 & 0.371 & 0.419 & 0.397 & 0.371 \\
\hline Inter-annual CV & \multicolumn{9}{|c|}{ RCP 8.5 Scenario } \\
\hline Intra-annual CV & 0.998 & 0.427 & 0.434 & 0.419 & 0.407 & 0.375 & 0.998 & 0.510 & 0.375 \\
\hline Inter-annual CV & 0.334 & 0.158 & 0.118 & 0.101 & 0.116 & 0.142 & 0.334 & 0.161 & 0.101 \\
\hline
\end{tabular}

Most of the CVs for the RCP 8.5 scenario (except those for MRI-CGCM3-MR) are higher than the CVs for the baseline scenario. The annual streamflow increase is rather high and has, therefore, been assessed by investigating the intra-annual and inter-annual variability of streamflow, which was high for RCP 8.5.

Table 1 shows that the averaged intra-annual variability for RCP 8.5 for high uncertainty is 0.510 , which is higher than 0.399 of the six estimates of the intra-annual variability for the baseline. Similarly, the averaged inter-annual variability for RCP 8.5 for high uncertainty is 0.161 , which is also higher than 0.136 of the six estimates of the inter-annual variability for the baseline. In the same way, most of the CV for the RCP 8.5 scenario (except those for MRI-CGCM3-MR) are higher than the CV for the baseline scenario. Most simulations indicate that intra-annual and inter-annual streamflow variability will increase in the future for RCP 8.5 by a considerable margin.

The results revealed a huge uncertainty of the future for the KRB. The KRB is faced with two scenarios based on RCP 8.5 which is the unrestricted policy for high uncertainty and strong consensus with implications for floods and drought, respectively. The overview of results analysed under high uncertainty show that climate change may result in floods in the basin. The KRB baseline period shows years of floods and drought that have been reported in the past. The predicted potential floods are expected to be more severe than the historical floods. This may lead to more severe damage to infrastructure, food crops, ecosystems, and possibly loss of lives if adequate adaptation and mitigation strategies are not put in place. Water quality is also likely to be altered and more low-lying areas are expected to be inundated. The predicted high temperatures in the basin may have implications of high evapotranspiration from vegetation and high evaporation from surface water bodies. This scenario requires strengthening of flood early warning systems to help in adaptation and mitigation.

The climate change scenario under strong consensus shows a status quo where streamflow is likely to remain the same. However, the basin water resources may be more stressed due to the increased water demand and possible rise in evapotranspiration. The scenario of drought will culminate into high aridity and drying up of some rivers and streams, as well as boreholes, leading to water shortages in some communities that largely depend on groundwater points. Agriculture productivity may be negatively affected and lead to food insecurity. Water levels in reservoirs may drastically be reduced affecting hydropower generation capacity and therefore subsequently affecting the ecosystem, some mining activities, water supply, and small-scale industries in KRB.

\subsection{Main Limitations of the Study}

The GCM, Access1-0 under RCP 8.5 had simulated higher magnitudes of streamflow compared to the other five GCMs, indicating uncertainties, and a conclusion was made based on strong consensus and high uncertainty. The streamflow results for RCP 8.5 
showed uncertainty in magnitude, which was also observed by other researchers who stated that there is uncertainty in magnitude and direction of change in the Zambezi River basin response to future GCM projections [43,44]. It was pointed out that GCM runs performed under RCP 8.5 result in more uncertainty than under RCP 4.5 because of climate distribution [17]. The simulation of Access1-0 under RCP 8.5 was considered to be a unique model skill (1).

\section{Conclusions}

The detailed analysis of streamflow under high resolution for strong consensus and high uncertainty is considered a novelty. The generated new knowledge for streamflow variability under various scenarios could be useful for future water resources planning and contribute to the preparation of realistic adaptation measures for the basin.

The projected changes in temperature show an increasing trend with minor uncertainties, while showing considerable uncertainties in precipitation. The basin for the RCP 8.5 scenario shows significant changes in streamflow based on high uncertainty and strong consensus among the ensemble streamflow simulations and strong consensus where the five GCM streamflow have good agreement. There are also significant increases in seasonal stream flows that range between $34 \%$ and $134 \%$ as analyzed from the ensemble mean of RCP 8.5 under high uncertainty, while the seasonal increases under the strong consensus range between $2 \%$ and $10 \%$

The basin for the RCP 4.5 scenario will be subjected to insignificant changes in monthly, seasonal and annual flow regimes and magnitudes. The predictions suggest that the magnitude and temporal streamflow will be slightly less than the baseline magnitude. The RCP 4.5 future climate scenario predicts a negligible reduction in streamflow for the basin whether simulated as individual GCM or ensemble mean.

The predicted high stream flows for RCP 8.5 under high uncertainty and moderate rise in stream flow under strong consensus suggest the need for adaptation plans and mitigation strategies. In contrast, the stream flows predicted for RCP 4.5 will require the review of current management strategies of water resources in the basin, considering the ever-increasing water demand and other impacts, such as on water quality. Most simulations indicate that intra-annual and inter-annual streamflow variability will decrease in the future for RCP 4.5, while increasing for RCP 8.5 for both cases (high uncertainty and strong consensus) by a considerable margin.

Temperature was predicted with a robust change signal, while precipitation was very variable with huge uncertainties, especially for the RCP 8.5 scenario. The future studies need to focus on RCP 4.5 and RCP 8.5 for the period 2050-2090 to assess any possible climate change impacts, such as temperature change on streamflow, that would arise from the corresponding scenarios. It is also recommended to analyse the effects of landuse/land cover changes on water resources and to increase the number of GCM projections to find a better consensus and possible uncertainty for analysis of future hydrology and water resources.

Author Contributions: Conceptualization, G.Z.N. and Y.E.W.; methodology, G.Z.N. and Y.E.W.; software, G.Z.N.; validation, G.Z.N. and Y.E.W.; formal analysis, G.Z.N. and Y.E.W.; investigation, G.Z.N. and Y.E.W.; data curation, G.Z.N.; writing—original draft preparation, G.Z.N.; writingreview and editing, Y.E.W.; visualization, G.Z.N. All authors have read and agreed to the published version of the manuscript.

Funding: This research received no external funding.

Institutional Review Board Statement: Not applicable.

Informed Consent Statement: Not applicable.

Data Availability Statement: Available upon a request from corresponding author.

Acknowledgments: We sincerely thank Central University of Technology, Free State, for the support. 
Conflicts of Interest: The authors declare no conflict of interest.

\section{References}

1. Lutz, A.F.; ter Maat, H.W.; Biemans, H.; Shrestha, A.B.; Wester, P.; Immerzeel, W.W. Selecting representative climate models for climate change impact studies: An advanced envelope-based selection approach. Int. J. Clim. 2016, 36, 3988-4005. [CrossRef]

2. Chien, H.; Yeh, P.J.-F.; Knouft, J.H. Modeling the potential impacts of climate change on streamflow in agricultural watersheds of the Midwestern United States. J. Hydrol. 2013, 491, 73-88. [CrossRef]

3. Kusangaya, S.; Warburton, M.L.; van Garderen, E.A.; Jewitt, G. Impacts of climate change on water resources in southern Africa: A review. Phys. Chem. Earth Parts A/B/C 2014, 67-69, 47-54. [CrossRef]

4. Goosse, H.; Barriat, P.Y.; Lefebvre, W.; Loutre, M.F.; Zunz, V. Modelling the Climate System. In Introduction to Climate Dynamics and Climate Modeling; Universite Catholique de Louvain: Louvain, Belgium, 2010; Chapter 3; pp. 59-86. ISBN 9781107445833. Available online: http:/ / www.climate.be/textbook (accessed on 4 February 2021).

5. Moss, R.H.; Edmonds, J.A.; Hibbard, K.A.; Manning, M.R.; Rose, S.K.; van Vuuren, D.P.; Carter, T.R.; Emori, S.; Kainuma, M.; Kram, T.; et al. The next generation of scenarios for climate change research and assessment. Nat. Cell Biol. 2010, 463, 747-756. [CrossRef] [PubMed]

6. Meinshausen, M.; Smith, S.J.; Calvin, K.; Daniel, J.S.; Kainuma, M.L.T.; Lamarque, J.F.; Matsumoto, K.; Montzka, S.A.; Raper, S.C.B.; Riahi, K.; et al. The RCP greenhouse gas concentrations and their extensions from 1765 to 2300. Clim. Chang. 2011, 109, 213-241. [CrossRef]

7. Van Vuuren, D.P.; Edmonds, J.; Kainuma, M.; Riahi, K.; Thomson, A.; Hibbard, K.; Hurtt, G.C.; Kram, T.; Krey, V.; Lamarque, J.-F.; et al. The representative concentration pathways: An overview. Clim. Chang. 2011, 109, 5-31. [CrossRef]

8. Musie, M.; Sen, S.; Srivastava, P. Application of CORDEX-AFRICA and NEX-GDDP datasets for hydrologic projections under climate change in Lake Ziway sub-basin, Ethiopia. J. Hydrol. Reg. Stud. 2020, 31, 100721. [CrossRef]

9. Murthy, C. Climate Change and Catchment Hydrology. Irish Climate Analysis and Research Unit (ICARUS); Department of Geography, National University of Ireland: Maynooth, Ireland, 2012. Available online: http://mural.maynoothuniversity.ie/4890/1/CM_ Climate_Change.pdf (accessed on 10 January 2020).

10. Fan, F.M.; Collischonn, W.; Meller, A.; Botelho, L.C.M. Ensemble streamflow forecasting experiments in a tropical basin: The São Francisco river case study. J. Hydrol. 2014, 519, 2906-2919. [CrossRef]

11. Saddique, N.; Usman, M.; Bernhofer, C. Simulating the Impact of Climate Change on the Hydrological Regimes of a Sparsely Gauged Mountainous Basin, Northern Pakistan. Water 2019, 11, 2141. [CrossRef]

12. Gosling, S.N.; Taylor, R.G.; Arnell, N.W.; Todd, M.C. A comparative analysis of projected impacts of climate change on river runoff from global and catchment-scale hydrological models. Hydrol. Earth Syst. Sci. 2011, 15, 279-294. [CrossRef]

13. Lespinas, F.; Ludwig, W.; Heussner, S. Hydrological and climatic uncertainties associated with modeling the impact of climate change on water resources of small Mediterranean coastal rivers. J. Hydrol. 2014, 511, 403-422. [CrossRef]

14. Li, Z.; Jin, J. Evaluating climate change impacts on streamflow variability based on a multisite multivariate GCM downscaling method in the Jing River of China. Hydrol. Earth Syst. Sci. 2017, 21, 5531-5546. [CrossRef]

15. Gautam, S.; Costello, C.; Baffaut, C.; Thompson, A.; Svoma, B.M.; Phung, Q.A.; Sadler, E.J. Assessing Long-Term Hydrological Impact of Climate Change Using an Ensemble Approach and Comparison with Global Gridded Model-A Case Study on Goodwater Creek Experimental Watershed. Water 2018, 10, 564. [CrossRef]

16. Hamududu, B.H. Impacts of Climate Change on Water Resources and Hydropower Systems in Central and Southern Africa; Norwegian University of Science and Technology: Trondheim, Norway, 2012.

17. Fant, C.; Gebretsadik, Y.; McCluskey, A.; Strzepek, K. An uncertainty approach to assessment of climate change impacts on the Zambezi River Basin. Clim. Chang. 2015, 130, 35-48. [CrossRef]

18. Githui, F.; Gitau, W.; Mutua, F.; Bauwens, W. Climate change impact on SWAT simulated streamflow in western Kenya. Int. J. Clim. 2009, 29, 1823-1834. [CrossRef]

19. Ndhlovu, G.; Woyessa, Y. Modelling impact of climate change on catchment water balance, Kabompo River in Zambezi River Basin. J. Hydrol. Reg. Stud. 2019, 27, 100650. [CrossRef]

20. Ngongondo, C.; Li, L.; Gong, L.; Xu, C.-Y.; Alemaw, B.F. Flood frequency under changing climate in the upper Kafue River basin, southern Africa: A large scale hydrological model application. Stoch. Environ. Res. Risk Assess. 2013, 27, 1883-1898. [CrossRef]

21. Ndhlovu, G.; Woyessa, Y. Use of gridded climate data for hydrological modelling in the Zambezi River Basin, Southern Africa. J. Hydrol. 2021, 602, 126749. [CrossRef]

22. World Bank. The Zambezi River Basin-A Multi-Sector Investment Opportunity Analysis; The World Bank: Washington, DC, USA, 2010. Available online: http://documents.worldbank.org/curated/en/724861468009989838/Summary-report (accessed on 12 October 2018).

23. Kapangaziwiri, E.; Mokoena, M.P.; Kahinda, J.M.; Hughes, D.A. An Evaluation for Use in South Africa. WRC Report; ECOMAG; Water Research Commission: Gezina, South Africa, 2013; pp. 1-59.

24. Young, T.; Tucker, T.; Galloway, M.; Manyike, P. Climate Change and Health in SADC. (September). 2010. Available online: http:/ / www.sead.co.za/downloads/climate-change-2010.pdf (accessed on 12 December 2019).

25. Moriasi, D.N.; Arnold, J.G.; Van Liew, M.W.; Bingner, R.L.; Harmel, R.D.; Veith, T.L. Model Evaluation Guidelines for Systematic Quantification of Accuracy in Watershed Simulations. Trans. Am. Soc. Agric. Biol. Eng. 2007, 50, 885-900. [CrossRef] 
26. Gassman, P.W.; Reyes, M.R.; Green, C.H.; Arnold, J.G. The Soil and Water Assessment Tool: Historical Development, Applications, and Future Research Directions. Trans. ASAE 2007, 50, 1211-1250. [CrossRef]

27. Neitsch, S.L.; Arnold, J.G.; Kiniry, J.R.; Williams, J.R. Soil and Water Assessment Tool User's Manual Version 2005. In Proceedings of the Diffuse Pollution Conference, Dublin, Ireland, 26 June-1 July 2005.

28. Arnold, J.G.; Moriasi, D.N.; Gassman, P.W.; Abbaspour, K.C.; White, M.J.; Srinivasan, R.; Santhi, C.; Harmel, R.D.; van Griensven, A.; Van Liew, M.W.; et al. SWAT: Model Use, Calibration, and Validation. Trans. ASABE 2012, 55, 1491-1508. [CrossRef]

29. Winchell, M.; Srinivasan, R.; Di Luzio, M.; Arnold, J.G. Arcswat Interface for SWAT2012: User's Guide. Blackland Research Center, Texas AgriLife Research, College Station, pp. 1-464. Available online: https://www.scirp.org/(S(351jmbntvnsjt1aadkposzje))/ reference/ReferencesPapers.aspx?ReferenceID=1935534 (accessed on 12 September 2021).

30. Waichler, S.R.; Wigmosta, M.S. Waichler, S.R.; Wigmosta, M.S. Development of hourly meteorological values from daily data and significance to hydrological modeling at HJ Andrews Experimental Forest. J. Exp. Forest. J. Hydromet 2003, 4, 251-263. [CrossRef]

31. Mehan, S.; Guo, T.; Gitau, M.W.; Flanagan, D.C. Comparative Study of Different Stochastic Weather Generators for Long-Term Climate Data Simulation. Climate 2017, 5, 26. [CrossRef]

32. Taylor, K.E.; Stouffer, R.J.; Meehl, G.A. An Overview of CMIP5 and the Experiment Design. Bull. Am. Meteorol. Soc. 2012, 93, 485-498. [CrossRef]

33. Khan, N.; Shahid, S.; Ahmed, K.; Ismail, T.; Nawaz, N.; Son, M. Performance Assessment of General Circulation Model in Simulating Daily Precipitation and Temperature Using Multiple Gridded Datasets. Water 2018, 10, 1793. [CrossRef]

34. NASA. NASA Earth Exchange Global Daily Downscaled Projections (NEX-GDDP) 1, 2015. Intent of This Document and POC. 2020. Available online: https://www.nccs.nasa.gov/services/data-collections/land-based-products/nex-gddp (accessed on 5 April 2020).

35. Abbaspour, K.C.; Rouholahnejad, E.; Vaghefi, S.; Srinivasan, R.; Yang, H.; Kløve, B. A continental-scale hydrology and water quality model for Europe: Calibration and uncertainty of a high-resolution large-scale SWAT model. J. Hydrol. 2015, 524, 733-752. [CrossRef]

36. Mei, Y.; Nikolopoulos, E.I.; Anagnostou, E.N.; Borga, M. Evaluating Satellite Precipitation Error Propagation in Runoff Simulations of Mountainous Basins. J. Hydrometeorol. 2016, 17, 1407-1423. [CrossRef]

37. Khan, R.S.; Bhuiyan, M.A.E. Artificial Intelligence-Based Techniques for Rainfall Estimation Integrating Multisource Precipitation Datasets. Atmosphere 2021, 12, 1239. [CrossRef]

38. Krysanova, V.; Donnelly, C.; Gelfan, A.; Gerten, D.; Arheimer, B.; Hattermann, F.; Kundzewicz, Z.W. How the performance of hydrological models relates to credibility of projections under climate change. Hydrol. Sci. J. 2018, 63, 696-720. [CrossRef]

39. Anandhi, A.; Frei, A.; Pierson, D.C.; Schneiderman, E.M.; Zion, M.S.; Lounsbury, D.; Matonse, A.H. Examination of change factor methodologies for climate change impact assessment. Water Resour. Res. 2011, 47, 1-10. [CrossRef]

40. Nash, J.; Sutcliffe, J. River flow forecasting through conceptual models part I-A discussion of principles. J. Hydrol. 1970, 10, 282-290. [CrossRef]

41. Tan, M.L.; Gassman, P.W.; Cracknell, A.P. Assessment of Three Long-Term Gridded Climate Products for Hydro-Climatic Simulations in Tropical River Basins. Water 2017, 9, 229. [CrossRef]

42. Narsimlu, B.; Gosain, A.K.; Chahar, B.R.; Singh, S.K.; Srivastava, P.K. SWAT Model Calibration and Uncertainty Analysis for Streamflow Prediction in the Kunwari River Basin, India, Using Sequential Uncertainty Fitting. Environ. Process 2015, 2, 79-95. [CrossRef]

43. Banze, F.; Guo, J.; Xiaotao, S. Variability and trends of rainfall, precipitation and discharges over zambezi river basin, southern africa: Review. Int. J. Hydrol. 2018, 2, 1. [CrossRef]

44. Tirivarombo, S. Hydrological Impacts of Climate Change in The Zambezi River Basin. Int. J. Sci. Res. Innov. Technol. 2017, 4, $60-75$.

45. Hidalgo, H.G.; Das, T.; Dettinger, M.D.; Cayan, D.R.; Pierce, D.W.; Barnett, T.P.; Bala, G.; Mirin, A.A.; Wood, A.; Bonfils, C.; et al. Detection and Attribution of Streamflow Timing Changes to Climate Change in the Western United States. J. Clim. 2009, 22, 3838-3855. [CrossRef]

46. Garcia, R.A.; Burgess, N.D.; Cabeza, M.; Rahbek, C.; Araújo, M.B. Exploring consensus in 21st century projections of climatically suitable areas for African vertebrates. Glob. Chang. Biol. 2012, 18, 1253-1269. [CrossRef]

47. Tadross, M.; Suarez, P.; Lotsch, A.; Hachigonta, S.; Mdoka, M.; Unganai, L.; Muchinda, M. Changes in grow-ing-season rainfall characteristics and downscaled scenarios of change over southern Africa: Implications for growing maize. In IPCC Regional Expert Meeting on Regional Impacts, Adaptation, Vulnerability, and Mitigation; IPCC: Nadi, Fiji, 2015; pp. 193-204. Available online: https: / / www.researchgate.net/publication/266465938 (accessed on 7 March 2021).

48. Usman, M.; Reason, C. Dry spell frequencies and their variability over southern Africa. Clim. Res. 2004, 26, 199-211. [CrossRef]

49. Maure, G.A.; Pinto, I.; Ndebele-Murisa, M.R.; Muthige, M.; Lennard, C.; Nikulin, G.; Dosio, A.; Meque, A.O. The southern African climate under $1.5^{\circ} \mathrm{C}$ and $2{ }^{\circ} \mathrm{C}$ of global warming as simulated by CORDEX regional climate models. Environ. Res. Lett. 2018, 13, 065002. [CrossRef]

50. Berhanu, B.; Seleshi, Y.; Demisse, S.S.; Melesse, A.M. Flow Regime Classification and Hydrological Characterization: A Case Study of Ethiopian Rivers. Water 2015, 7, 3149-3165. [CrossRef] 